\title{
Tyrosine phosphorylation of cortactin by the FAK-Src complex at focal adhesions regulates cell motility
}

\author{
Wenqi Wang, Yang Liu and Kan Liao*
}

\begin{abstract}
Background: Cell migration plays an important role in many physiological and pathological processes, including immune cell chemotaxis and cancer metastasis. It is a coordinated process that involves dynamic changes in the actin cytoskeleton and its interplay with focal adhesions. At the leading edge of a migrating cell, it is the rearrangement of actin and its attachment to focal adhesions that generates the driving force necessary for movement. However, the mechanisms involved in the attachment of actin filaments to focal adhesions are still not fully understood.

Results: Signaling by the FAK-Src complex plays a crucial role in regulating the formation of protein complexes at focal adhesions to which the actin filaments are attached. Cortactin, an F-actin associated protein and a substrate of Src kinase, was found to interact with FAK through its SH3 domain and the C-terminal proline-rich regions of FAK. We found that the autophosphorylation of Tyr ${ }^{397}$ in FAK, which is necessary for FAK activation, was not required for the interaction with cortactin, but was essential for the tyrosine phosphorylation of the associated cortactin. At focal adhesions, cortactin was phosphorylated at tyrosine residues known to be phosphorylated by Src. The tyrosine phosphorylation of cortactin and its ability to associate with the actin cytoskeleton were required in tandem for the regulation of cell motility. Cell motility could be inhibited by truncating the N-terminal F-actin binding domains of cortactin or by blocking tyrosine phosphorylation (Y421/466/475/482F mutation). In addition, the mutant cortactin phosphorylation mimic (Y421/466/475/482E) had a reduced ability to interact with FAK and promoted cell motility. The promotion of cell motility by the cortactin phosphorylation mimic could also be inhibited by truncating its $\mathrm{N}$-terminal F-actin binding domains.

Conclusions: Our results suggest that cortactin acts as a bridging molecule between actin filaments and focal adhesions. The cortactin N-terminus associates with F-actin, while its C-terminus interacts with focal adhesions. The tyrosine phosphorylation of cortactin by the FAK-Src complex modulates its interaction with FAK and increases its turnover at focal adhesions to promote cell motility.
\end{abstract}

Keywords: cortactin, cortactin tyrosine phosphorylation, FAK, FAK-Src complex, focal adhesions, cell motility

\section{Background}

Src is a non-receptor cytoplasmic tyrosine kinase activated by integrins and receptor tyrosine kinases [1]. In normal cells, Src is involved in a vast range of physiological functions, including cell proliferation, cytoskeletal regulation, cell shape control, cell-matrix adhesion

\footnotetext{
* Correspondence: kliao@sibs.ac.cn

State Key Laboratory of Molecular Biology, Institute of Biochemistry and Cell Biology, Shanghai Institutes for Biological Sciences, Chinese Academy of Sciences, Shanghai 200031, China
}

(c) 2011 Wang et al; licensee BioMed Central Ltd. This is an Open Access article distributed under the terms of the Creative Commons Attribution License (http://creativecommons.org/licenses/by/2.0), which permits unrestricted use, distribution, and reproduction in any medium, provided the original work is properly cited. dynamics and motility [2,3]. In many types of human cancer, Src is overexpressed or hyperactivated $[4,5]$. The prominent role of Src in regulating cytoskeletal dynamics and cell motility makes the study of Src indispensable in understanding cancer cell migration and invasion.

Initially identified as a tyrosine-phosphorylated protein in v-Src infected chicken embryo fibroblasts [6], cortactin is a direct substrate of cellular Src kinase [7]. It is phosphorylated by Src at three tyrosine residues $\left(\mathrm{Tyr}^{421}\right.$,

\section{() Biomed Central}


466, 482 of murine cortactin) in vitro [8]. The phosphorylation of $\mathrm{Tyr}^{475}$ was identified by a mass spectrometry study [9]. These tyrosine phosphorylation sites reside in the proline-rich region, which is the least conserved domain in cortactin from different species [10].

Many studies have suggested that cortactin and its tyrosine phosphorylation regulate lamellipodial protrusion, cell spreading, intercellular adhesion and cell motility [11-13]. Src-catalyzed cortactin tyrosine phosphorylation is involved in integrin-mediated cell adhesion and spreading [14]. Cortactin knockdown in murine fibroblasts impairs both random and directional cell migration [15]. The expression of cortactin mutated at Src phosphorylation sites (Y421/466/482F) decreases cell motility in ECV304 endothelial cells [8]. The impaired cell motility in cortactin knockdown gastric cancer cell lines, with a low cortactin phosphorylation level, can be rescued by the ectopic expression of wild-type cortactin, but not by the mutant cortactin (Y421/466/482F) [16].

Early studies revealed that cortactin colocalizes with Factin in the cortical structures of adherent cells [7,17]. It associates with the F-actin cytoskeleton through the Factin binding tandem cortactin repeats and the N-terminal acidic domain that interacts with the actin-related protein (Arp) 2/3 complex for dendritic actin nucleation $[10,18,19]$. At the cell periphery, the F-actin cytoskeleton forms a highly organized meshwork that controls membrane protrusion and regulates cell motility [20,21]. During cell migration, the propelling force is generated by membrane protrusions and by membrane-matrix adhesions, called focal adhesions, at which transmembrane integrins link the extracellular matrix to the intracellular actin cytoskeleton [22].

In contrast to the cortactin that colocalizes with Factin at cortical regions, tyrosine phosphorylated cortactin ( $\left.\mathrm{pTyr}^{421}, 466,482\right)$ is almost exclusively localized at focal adhesions [16,23]. It is colocalized with paxillin and vinculin at the ends of F-actin stress fibers [16,23]. At focal adhesions, the clustered integrins recruit FAK and facilitate its activation, forming an active FAK-Src complex that initiates many intracellular signaling events [24-27]. The autophosphorylation of FAK at $\mathrm{Tyr}^{397}$ creates a high affinity binding site for the Srchomology 2 domain of Src kinase [28]. The binding of Src to FAK leads to the formation of an active FAKSrc complex in which the active Src kinase trans-phosphorylates FAK at $\mathrm{Tyr}^{576,577}$ for maximal FAK catalytic activity [29].

FAK recruits adaptor proteins and signaling molecules into focal adhesions, at which many are phosphorylated by the FAK-Src complex. The N-terminal FERM domain binds to growth factor receptors, the C-terminal FAT domain interacts with talin and paxillin, and the proline-rich regions recruit Src-homology 3 (SH3) domain- containing proteins, such as p130Cas, GRAF and ASAP1 [26,30].

In this study, we report that cortactin interacted with FAK at focal adhesions at which it is phosphorylated by the FAK-Src complex. Cortactin helps mediate the association of F-actin with focal adhesions. Its N-terminus interacts with $\mathrm{F}$-actin, and its $\mathrm{C}$-terminus associates with FAK. The tyrosine phosphorylation of cortactin by the FAK-Src complex reduces its interaction with FAK, most likely to increase its turnover at focal adhesions to promote cell motility.

\section{Results}

Colocalization of tyrosine phosphorylated cortactin and the active FAK-Src complex at focal adhesions

Cortactin, Src and actin are colocalized at the leading edge of lamellipodia in several types of cells, including COS7 cells (Figure 1A) [11]. In contrast, the tyrosine phosphorylated cortactin (at Src kinase site $\mathrm{Tyr}^{421}$ ) clustered into dots, which were localized to focal adhesions marked by paxillin (Figure 1D) [23]. The phosphorylated cortactin at focal adhesions was phosphorylated at all three Src kinase sites $\left(\mathrm{Tyr}^{421}, 466\right.$, ${ }^{482}$ ) (Figure 2A) (the information about these antibodies is provided in the Methods section). It could be dephosphorylated by alkaline phosphatase. No signal was detected by antibodies against phosphorylated cortactin in alkaline phosphatase-treated cells (Figure 2A). In addition, the active Src kinase (phosphorylated at $\mathrm{Tyr}^{418}$ ) was also colocalized with focal adhesions (Figure 1D). The kinase and its product of phosphorylated cortactin were colocalized at focal adhesions to which actin stress fibers were attached.

Cortactin and its phosphorylated forms had very different cellular distribution pattern in cell, implicating additional functions for phosphorylated cortactin (Figure $1 \mathrm{E})$. At the lamellipodial leading edge, cortactin and its tyrosine phosphorylated forms had a different localization (Figure $1 \mathrm{~A}$ and $1 \mathrm{~B}$ ). Cortactin traced the lamellipodial edge. However, phosphorylated cortactin dotted the edge and was colocalized with paxillin and $\mathrm{Tyr}^{418}$-phosphorylated Src at the newly formed focal contacts (Figure $1 \mathrm{~B}$ and $1 \mathrm{C}$ ). During cell-matrix interactions, the clustering of integrins forms focal contacts, and then focal adhesions, at the leading edge of the lamellipodia [31]. At focal adhesions, Src binds to $\mathrm{Tyr}^{397}$-phosphorylated FAK to form an active FAK-Src complex (Figure $1 \mathrm{C}$ and 1D) $[26,28]$. The colocalization of tyrosine phosphorylated cortactin with $\mathrm{Tyr}^{418}$-phosphorylated Src at focal adhesions implicates Src in cortactin tyrosine phosphorylation at focal adhesions (Figure 1D). It was further supported by the colocalization of phosphorylated cortactin with $\mathrm{Tyr}^{397}$-autophosphorylated FAK (Figure 2B). 

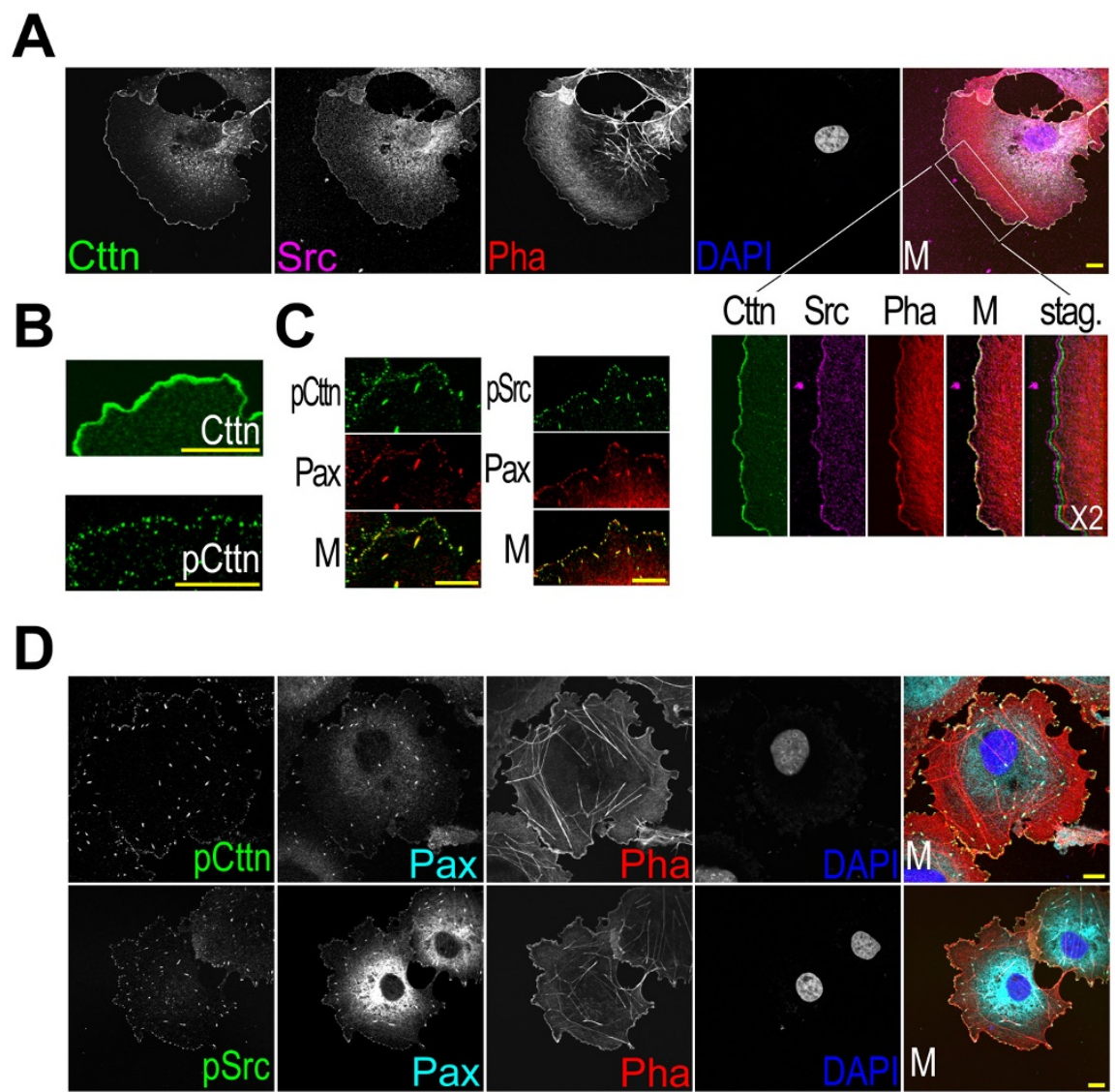

E

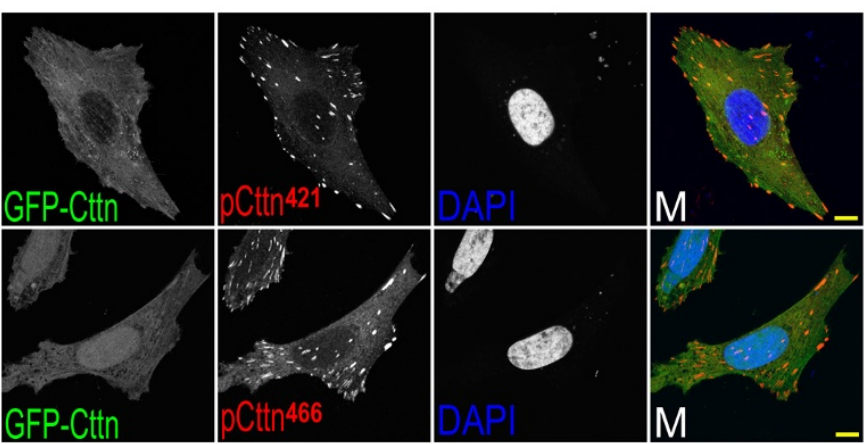

Figure 1 Colocalization of tyrosine phosphorylated cortactin and active Src at focal adhesions. Bar, $10 \mu m$. (A) Colocalization of cortactin Src and actin at the lamellipodial edge. COS7 cells were fixed with paraformaldehyde and Triton X-100, and stained with anti-cortactin antibody (Cttn), anti-Src antibody (Src), phalloidin (pha) and DAPI (DAPI). M, the merged picture; stag., the staggered picture. X2, 2 times enlargement. (B) The lamellipodial edge stained with an anti-cortactin (Cttn) or an anti-Tyr ${ }^{421}$-phosphorylated cortactin ( $\left.p C t t n\right)$ antibody. (C) Colocalization of $\mathrm{Tyr}^{421}$-phosphorylated cortactin ( $\left.p C t t n\right)$ and $\mathrm{Ty}^{418}$-phosphorylated Src (pSrc) at focal contacts at the lamellipodial edge. Pax, anti-paxillin antibody staining. (D) Colocalization of $\mathrm{Tyr}^{421}$-phosphorylated cortactin and $\mathrm{Tyr}^{418}$-phosphorylated Src at focal adhesions. (E) The immunofluorescence staining of $\mathrm{Tyr}^{421}$ or ${ }^{466}$-phosphorylated cortactin. COS7 cells expressing exogenous EGFP-tagged cortactin (GFP-Cttn) were stained with antiphosphotyrosine ${ }^{421}$ or anti-phosphotyrosine ${ }^{466}$ antibody $\left(p C t n^{421}, p C t n^{466}\right)$.

\section{Cortactin interacts with FAK and its tyrosine} phosphorylation reduces the interaction

Results from immunoprecipitation analysis indicated that cortactin interacts with FAK but not with paxillin (results not shown). Cortactin was clustered with FAK at newly formed focal adhesions at the leading lamellipodial edge of migrating cells (Figure 3A). To examine their interaction at focal adhesions, GFP-tagged 

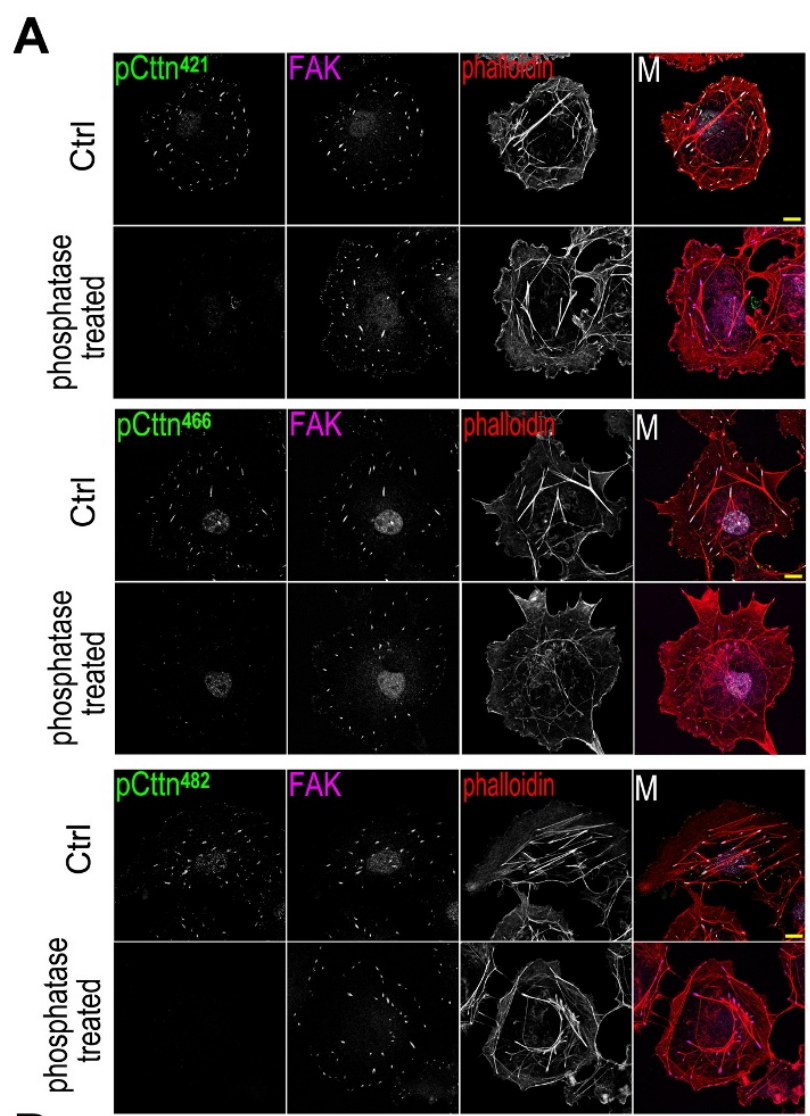

B

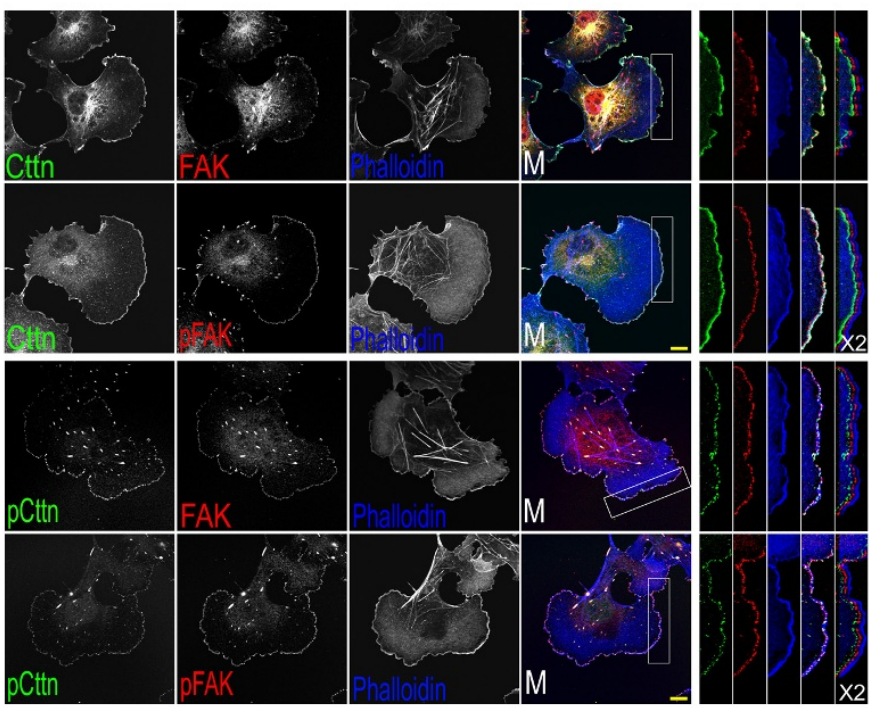

Figure 2 Colocalization of tyrosine phosphorylated cortactin and FAK at focal adhesions. Bar, $10 \mu \mathrm{m}$. (A) Dephosphorylation of Tyr $\mathrm{r}^{421,466}$ or 482 -phosphorylated cortactin by alkaline phosphatase. Fixed COS7 cells were treated with 0.5 unit/ $\mu$ l calf intestinal alkaline phosphatase in $1 \times$ TTBS (Tween/Tris-buffered saline, $25 \mathrm{mM}$ Tris-HCl, pH 7.5, $150 \mathrm{mM} \mathrm{NaCl}, 0.05 \%$ Tween and $0.001 \%$ thimerosal) for 1 hour at room temperature, and then immunofluorescence-labeled with anti-FAK antibody (FAK), phalloidin (phalloidin), and with an anti-phosphotyrosine ${ }^{421}$, antiphosphotyrosine ${ }^{466}$ or anti-phosphotyrosine ${ }^{482}$ cortactin antibody $\left(p \mathrm{Cttn}^{421}, p C \mathrm{ttn}^{466}, p C \mathrm{ttn}^{482}\right)$. C $\mathrm{trl}$, without alkaline phosphatase treatment. (B) Colocalization of $\mathrm{Tyr}^{421}$-phosphorylated cortactin with FAK at focal adhesions. FAK, anti-FAK antibody staining. pFAK, anti-Tyr ${ }^{397}$-phosphorylated FAK antibody staining. 

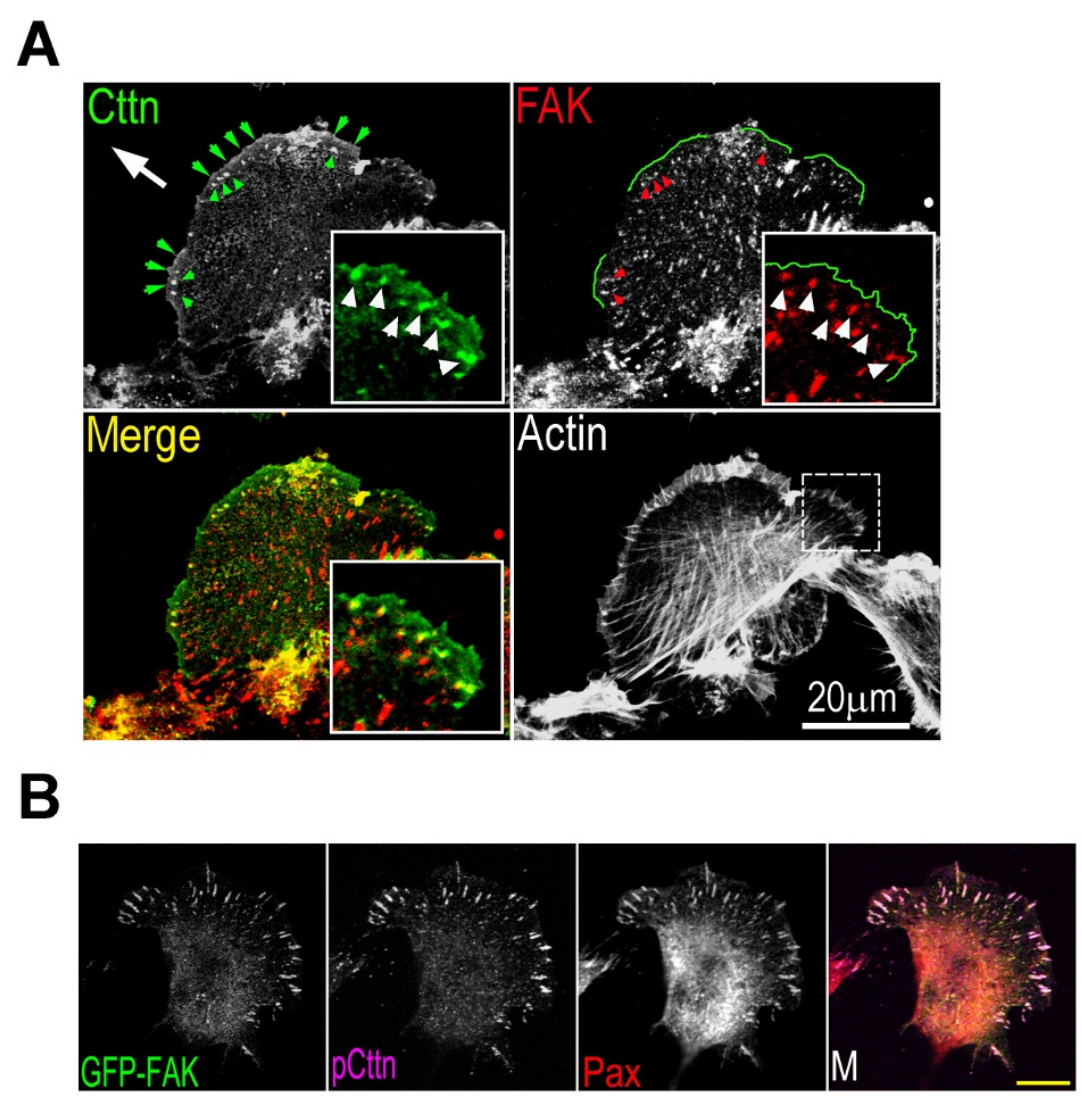

Figure 3 Cortactin clustering at nascent focal adhesions in migrating cells. (A) Immunofluorescence staining of cortactin and FAK on the leading edge of migrating HT1080 cells. Bar, $20 \mu \mathrm{m}$. The HT1080 cell monolayer was scratched with a rubber policeman. After 2 hours, the cells were fixed and stained with anti-cortactin antibody, anti-FAK antibody and phalloidin. The arrow indicates the direction of cell migration. The big arrowheads indicate the edge of lamellipodia, and the small arrowheads indicate focal adhesions. The insert represents the enlarged area. The images of the anti-cortactin and anti-FAK labeling are merged. (B) The localization of GFP-tagged FAK at focal adhesions. Bar, $20 \mu \mathrm{m}$. COS7 cells were transiently transfected with the GFP-tagged FAK expression vector and cells were fixed and stained with anti-cortactin (Cttn) and antipaxillin (Pax) antibodies. GFP-FAK, GFP fluorescence. $M$, merged picture.

cortactin mutants were expressed in COS7 cells, and the cellular extracts were immunoprecipitated using an antiFAK antibody (Figure 4A). As shown in Figure 4C, only the cortactin $\mathrm{C}$-terminus interacted with FAK. There was no interaction between the cortactin $\mathrm{N}$-terminal Factin binding domains and FAK.

The cortactin C-terminus contains two important functional domains: the proline-rich region containing Src kinase phosphorylation sites and the SH3 domain (7-10). The cortactin SH3 domain participates in the interaction with FAK. In GST pulldown experiments, the deletion of the $\mathrm{SH} 3$ domain reduced, but did not completely block, the interaction with FAK (Figure 4E). Cortactin tyrosine phosphorylation was not required for the interaction with FAK, but it regulated their interaction. The phosphorylation-incompetent cortactin (Y421/ 466/475/482F) bound FAK, similar to wild-type cortactin (Figure 4D). However, the cortactin phosphorylation mimic (Y421/466/475/482E) exhibited a much weaker association with FAK (Figure 4D). Thus, both the proline-rich region and the $\mathrm{SH} 3$ domain at the cortactin $\mathrm{C}$ terminus were important for the cortactin-FAK interaction.

The autophosphorylation of FAK at $\mathrm{Tyr}^{397}$ is essential for the binding to Src to form the FAK-Src complex. To determine if Src in the FAK-Src complex mediates the interaction between cortactin and FAK, $\mathrm{Tyr}^{397}$ in FAK was mutated. Exogenous GFP-tagged FAK was expressed in COS7 cells and was found to localize to focal adhesions (Figure 3B). In the GST pull-down assay, the GFP-tagged FAK and the GFP-tagged FAK mutant (Y397F) exhibited no difference in their association with GST-cortactin (Figure 4F), indicating that the interaction between cortactin and FAK is not mediated by Src.

Of the several functional domains in FAK, the cortactin-interaction domain resides in proline-rich regions 2 and 3 (Figure $4 \mathrm{~B}$ and $4 \mathrm{G}$ ). By mutating the proline 
residues in these regions ( $\mathrm{m} 1$ in proline-rich region 2 $\mathrm{P} 712 / 715 \mathrm{~A}, \mathrm{~m} 2$ in proline-rich region $3 \mathrm{P} 876 / 879 \mathrm{~A}$ and $\mathrm{m} 1 / 2 \mathrm{P} 712 / 715 / 876 / 879 \mathrm{~A})$, their interaction with cortactin was decreased (Figure $4 \mathrm{H}$ ). This suggests that the interaction between cortactin and FAK is mediated by the C-terminal domains of cortactin and proline-rich regions 2 and 3 of FAK, and that it is regulated by cortactin tyrosine phosphorylation.

\section{Cell adhesion induced cortactin tyrosine phosphorylation at focal adhesions}

Cell adhesion induces the formation of the FAK-Src complex, which leads to the phosphorylation of various FAK-associated proteins [26]. During the adhesion of suspended HEK293 cells in a fibronectin-coated dish, FAK autophosphorylation and the phosphorylation of FAK-associated p130Cas were both increased (Figure $5 \mathrm{~A}$ ). As a FAK associated protein, cortactin was also phosphorylated on tyrosine residues during this cell adhesion process (Figure 5B). The co-immunoprecipitation of FAK and its autophosphorylated form from adherent cells using an anti-cortactin antibody demonstrates the association of tyrosine phosphorylated cortactin with the FAK-Src complex (Figure 5C).

During the initial stage of cell adhesion and spreading, FAK, cortactin and actin were all colocalized at the edge of the membrane (Figure 5D). Cell adhesion induced FAK clustering and focal adhesion formation. FAK at focal adhesions was autophosphorylated (Figure 5D and $5 \mathrm{E})$. In these adherent cells, cortactin was still primarily localized to the cell cortex, and cortactin clustering could only be observed at newly formed focal contacts at the leading edge of the lamellipodia (Figure 3A and 5D). However, cortactin was tyrosine phosphorylated at focal adhesions (Figure 2 and 5E). The tyrosine phosphorylation of cortactin might decrease its interaction with FAK, because the cortactin phosphorylation mimic (Y421/466/475/482E) exhibited a much weaker association with FAK (Figure 4D).

\section{FAK-Src complex is required for cortactin tyrosine phosphorylation at focal adhesions}

To examine the function of the FAK-Src complex in cortactin tyrosine phosphorylation, FAK was knocked down by RNA interference in COS7 cells (Figure 5G and $5 \mathrm{H}$ ). Cortactin expression was not affected by FAK knockdown, but cortactin tyrosine phosphorylation was greatly reduced (Figure 5G). Because focal adhesions can still form in FAK-deficient cells [32], cortactin tyrosine phosphorylation at focal adhesions in FAK knockdown COS7 cells was analyzed by immunofluorescence staining. As shown in Figure $5 \mathrm{H}$, cortactin tyrosine phosphorylation was not detected at focal adhesions. In contrast, cortactin knockdown by RNA interference had no effect on FAK or its autophosphorylation (Figure 5F). Thus, these results suggest that at focal adhesions cortactin interacts with FAK, which is required for cortactin tyrosine phosphorylation.

FAK autophosphorylation at $\mathrm{Tyr}^{397}$ is essential for the formation of the FAK-Src complex. By mutating $\mathrm{Tyr}^{397}$ of FAK into Phe, the formation of the FAK-Src complex at focal adhesions can be disrupted [26]. In the GFP-tagged FAK (Y397F) mutant, autophosphorylation at $\mathrm{Tyr}^{397}$ was abolished and Src-catalyzed $\mathrm{Tyr}^{576}$ phosphorylation was inhibited (Figure 5I). However, the interaction of FAK with cortactin was not affected by the mutation at $\mathrm{Tyr}^{397}$ in GST pull-down experiments (Figure 4F), and the $\mathrm{Tyr}^{397}$-mutated FAK, overexpressed in COS7 cells, could be co-immunoprecipitated with cortactin by the anti-cortactin antibody (Figure 5J). Although cortactin could still interact with the mutant FAK, the mutation disrupted the interaction between FAK and Src, leading to a decrease in cortactin phosphorylation. Tyrosine phosphorylation in cortactin immunoprecipitated from COS7 cells overexpressing the mutant GFP-tagged FAK (Y397F) was dramatically reduced (Figure 5J). Thus, it appears that cortactin tyrosine phosphorylation at focal adhesions requires the formation of the FAK-Src complex.

To determine whether cortactin is phosphorylated by FAK or by Src in the FAK-Src complex, cortactin tyrosine phosphorylation was analyzed in HEK293 cells overexpressing GFP-tagged FAK, Src or both. The results of this experiment suggest that cortactin was phosphorylated by Src (Figure 6A). Furthermore, cortactin tyrosine phosphorylation could be promoted by expressing the constitutively active Src, but not the inactive Src. And mutating the Src phosphorylation sites in cortactin (Y421/466/475/482F) inhibited Src-catalyzed cortactin tyrosine phosphorylation (Figure 6B).

The activation of Src in the FAK-Src complex was designated by an increase in $\mathrm{Tyr}^{418}$-phosphorylated Src following cell adhesion (results not shown). Src was recruited to focal adhesions by $\mathrm{Tyr}^{397}$-autophosphorylated FAK to form the FAK-Src complex during cell adhesion (Figure 6C). Although cortactin interacted with FAK at focal adhesions, it was phosphorylated by Src kinase in the FAK-Src complex. In cells overexpressing active Src, most cortactin was phosphorylated and recruited to cortical focal adhesions (Figure 6D and 6E). In these cells, cortactin and its phosphorylated form were well co-localized. In contrast, the expression of inactive Src did not affect cortactin phosphorylation or the formation of focal adhesions (Figure 6E).

\section{Cell motility is regulated by FAK-Src complex-catalyzed cortactin tyrosine phosphorylation}

The FAK-Src complex holds the center stage in the regulation of cell motility [26]. Cell migration is inhibited 


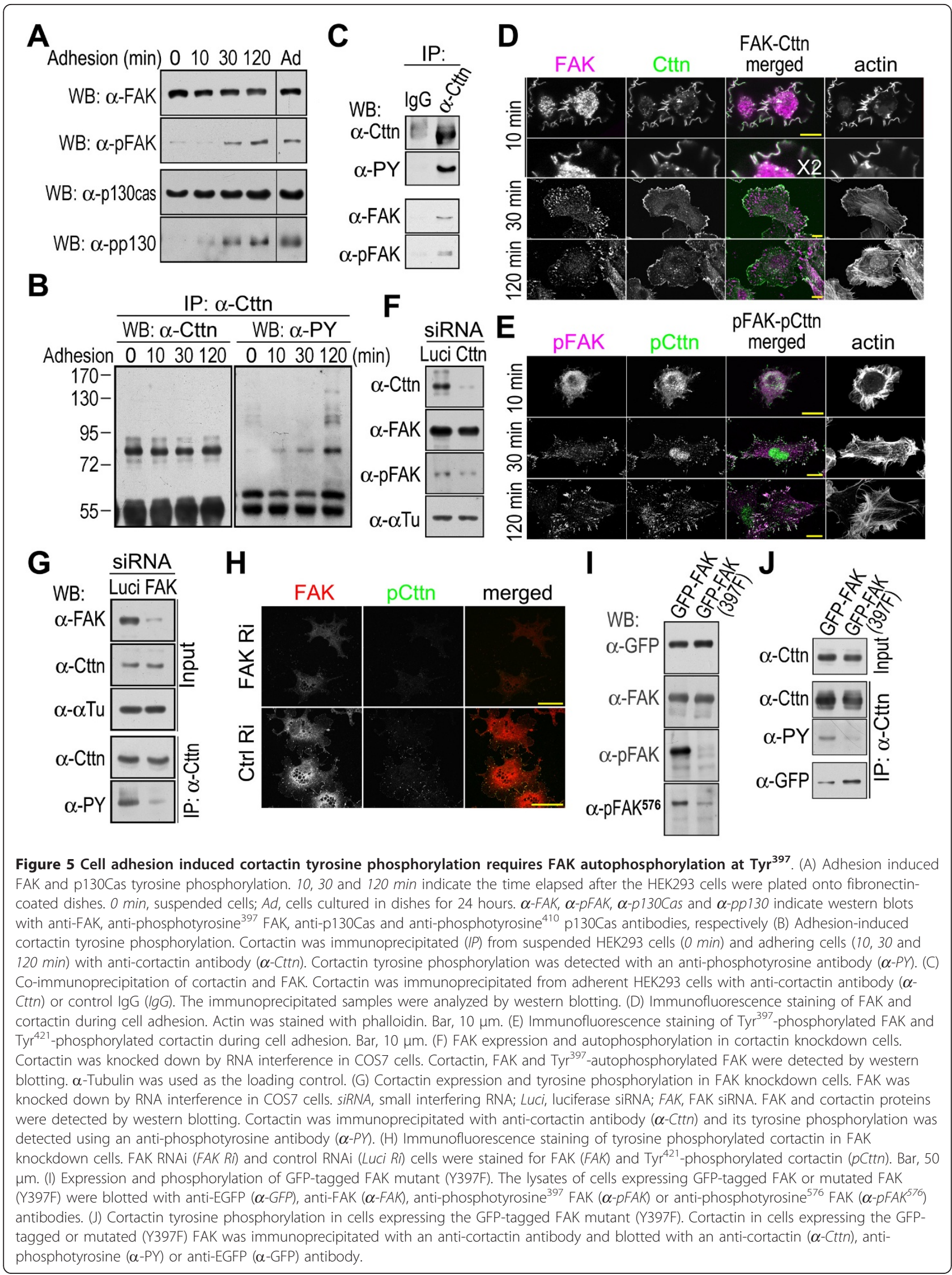




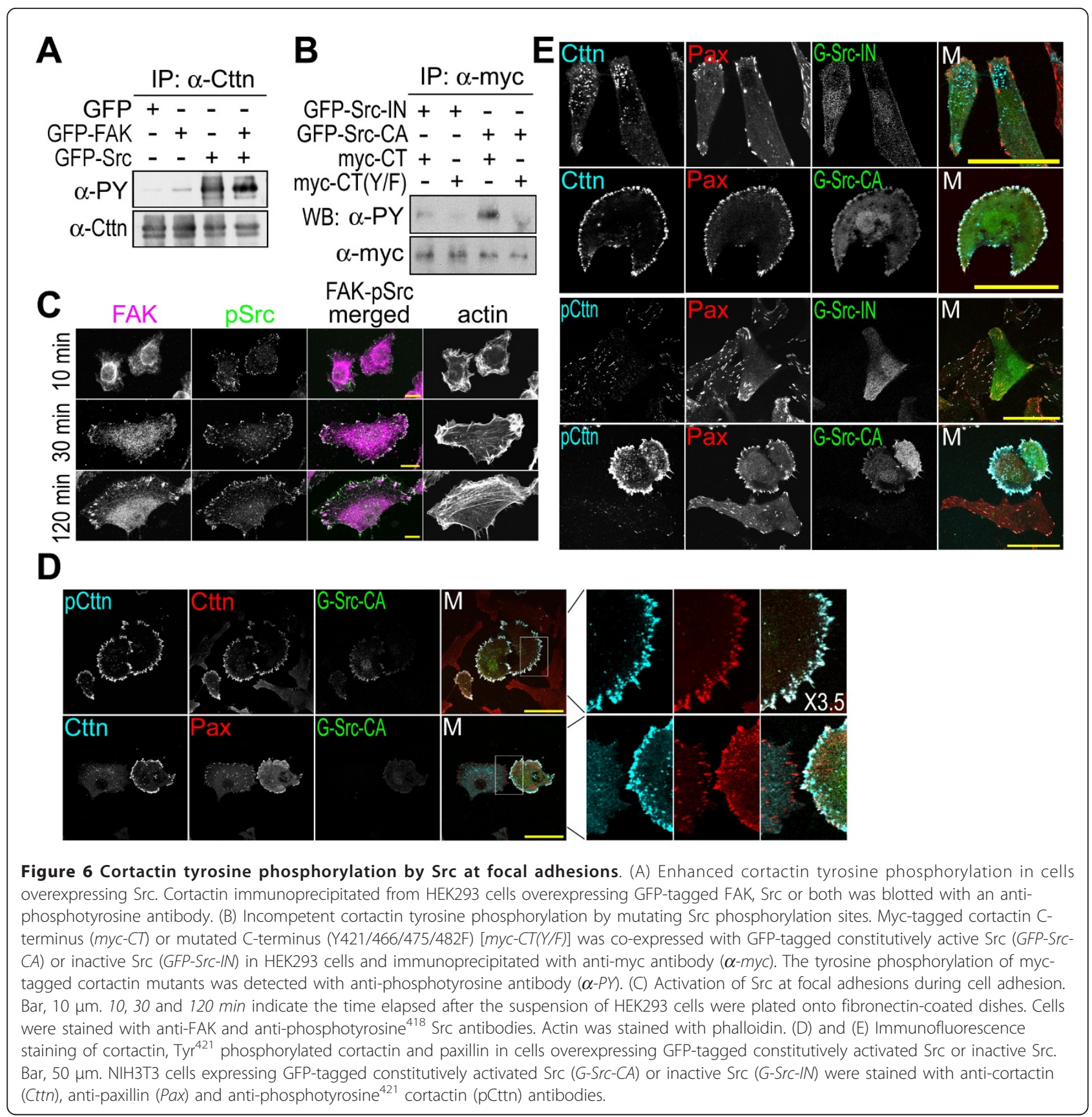

in FAK-deficient cells and in cells treated with the Src family kinase inhibitor, PP2 [32,33]. In HT1080 cells, FAK knockdown by RNA interference inhibited cell migration, as did inhibiting Src kinase activity with PP2 (Figure 7A, B and 7C). In addition, overexpressing the GFP-tagged FAK mutant (Y397F), which prevents formation of the FAK-Src complex, also inhibited cell migration (Figure 7D). As a substrate of the FAK-Src complex, cortactin was involved in regulating cell motility. Cortactin knockdown in HT1080 cells by RNA interference inhibited cell migration (Figure 7A and 7E).
Cortactin interacted with FAK and was phosphorylated by the FAK-Src complex (Figures 4 and 6). To investigate the role of FAK-Src complex-catalyzed cortactin tyrosine phosphorylation in cell motility, the phosphorylation sites in cortactin were mutated into Phe residues (Y421/466/475/482F) to block tyrosine phosphorylation. The Phe mutations in cortactin incompetent tyrosine phosphorylation by the FAK-Src complex, but did not block the interaction of cortactin with FAK (Figures 4D and 6B). Overexpressing the phosphorylation-incompetent cortactin mutant (Y421/466/475/ 


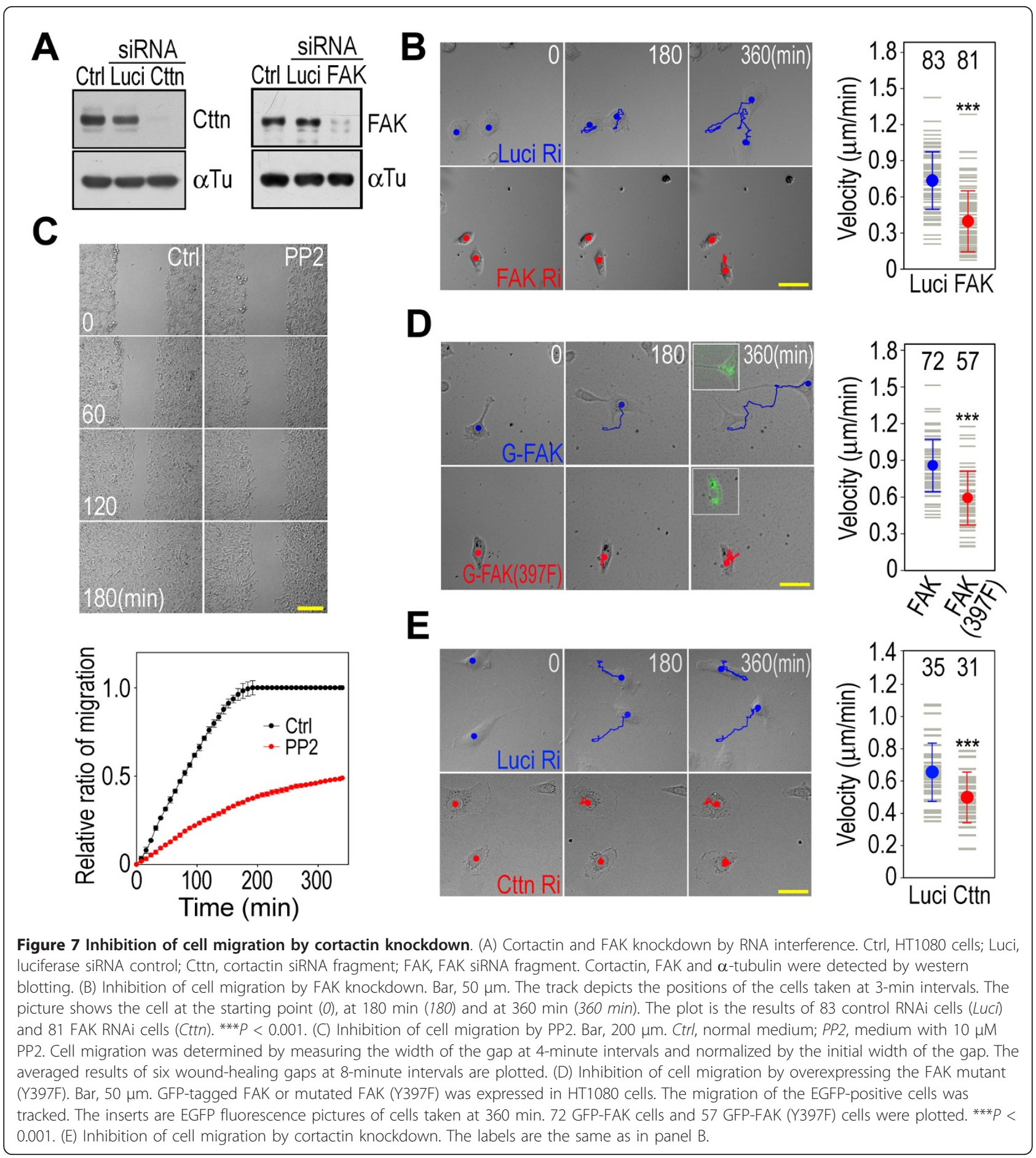

482F) in HT1080 cells inhibited cell migration (Figure $8 \mathrm{~A}$ and $8 \mathrm{~B}$ ), indicating that cortactin tyrosine phosphorylation regulates cell migration.

The tyrosine phosphorylation of cortactin by the FAKSrc complex most likely promotes its dissociation from FAK because the interaction between the cortactin phosphorylation mimic and FAK was greatly reduced
(Figure 4D). The phosphorylation-incompetent cortactin mutant (Y421/466/475/482F) formed a stable interaction with FAK, and cell migration was inhibited. In contrast, the cortactin phosphorylation mimic exhibited increased turnover at focal adhesions (Figure 4D) [34], greatly enhancing cell migration (Figure 8A and 8B). Overexpressing wild-type cortactin in HT1080 cells led to an 
A

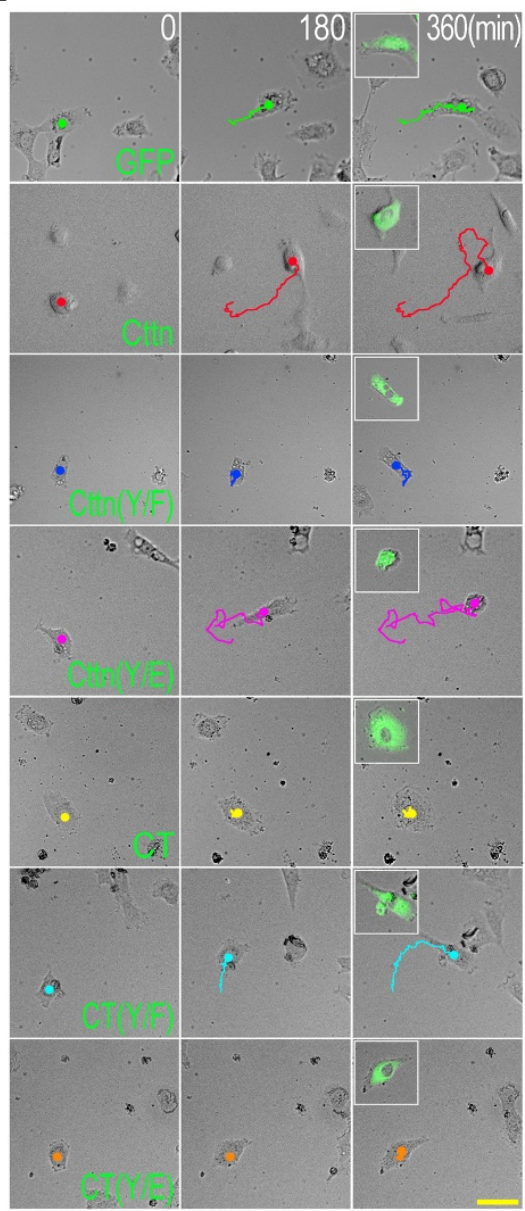

B
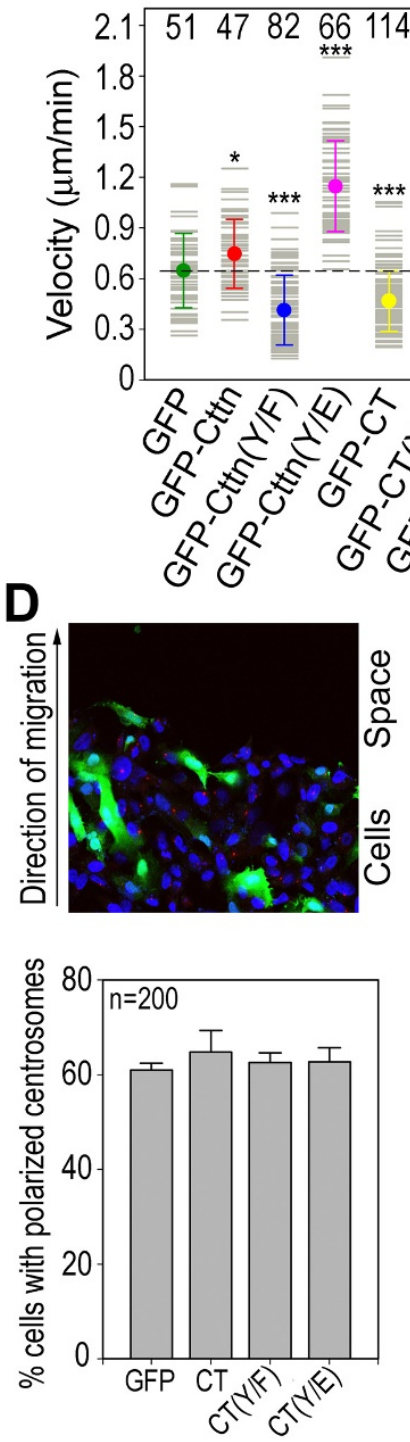

C
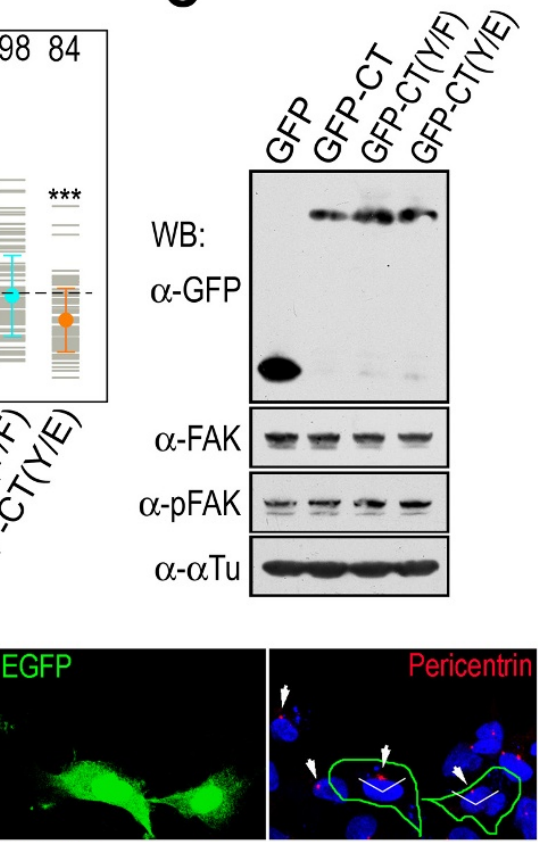

GFP-CT
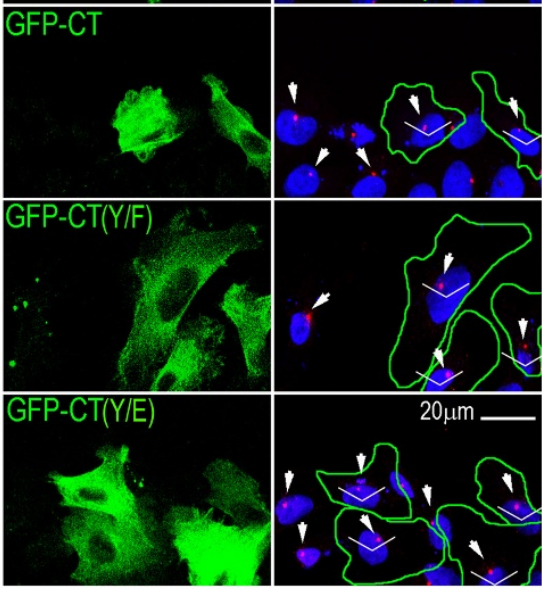

Figure 8 Inhibition of cell migration by blocking cortactin tyrosine phosphorylation. Tracks of live-cell recordings. Bar, $50 \mu \mathrm{m}$. The migration of HT1080 cells overexpressing EGFP (GFP), GFP-tagged cortactin (Cttn), the phosphorylation-incompetent cortactin mutant [Cttn(Y/F)], the cortactin phosphorylation mimic mutant $[\mathrm{Cttn}(\mathrm{Y} / \mathrm{E})]$ or their N-terminal truncated forms [CT, $C T(Y / F), C T(Y / E)]$ were tracked. The inserts are EGFP fluorescence picture of cells taken at $360 \mathrm{~min}$. (B) Plot of migration speed. The numbers are the EGFP positive cells plotted. The statistical analysis was made against the results of cells overexpressing EGFP. ${ }^{*} P<0.05$; ${ }^{* *} P<0.001$. (C) FAK and its autophosphorylation in cells overexpressing N-terminal truncated cortactin mutants. FAK and its autophosphorylation at $\mathrm{Tyr}^{397}$ in HT1080 cells overexpressing EGFP or GFPtagged cortactin C-terminus mutants were analyzed by western blotting. (D) Centrosome orientation in migrating cells expressing GFP-tagged cortactin C-terminus mutants. HT1080 cells transfected with vector expressing GFP protein (EGFP), GFP-tagged cortactin C-terminus (GFP-CT), phosphorylation-incompetent C-terminus (Y421/466/475/482F) [GFP-CT(Y/F)] or phosphorylation mimicking C-terminus (Y421/466/475/482E) [GFP$C T(Y / E)]$ were subjected to wound-healing analysis. The centrosome (stained with anti-pericentrin antibody) in the GFP-positive cell at the migration front was analyzed. Cells with centrosomes located within $120^{\circ}$ of the migration direction were counted as polarized, and 200 cells were plotted for each cortactin mutant.

increase in cellular cortactin, which might increase levels of the phosphorylated form, thereby slightly enhancing cell migration (Figure 8A and 8B). Taken together, these results suggest that tyrosine phosphorylation of cortactin regulates cell motility by increasing cortactin turnover at focal adhesions.

Cortactin interacts with $\mathrm{F}$-actin through its $\mathrm{N}$-terminal F-actin binding domains [10]. In order to understand 
the effects of cortactin turnover on F-actin dynamics at focal adhesions, the cortactin $\mathrm{N}$-terminal domains were truncated to disrupt its interaction with F-actin. Without these domains, the remaining cortactin $\mathrm{C}$-terminus could still interact with FAK and could be phosphorylated by the FAK-Src complex (Figures $4 \mathrm{C}$ and 6B). However, cell migration was inhibited by overexpressing the cortactin C-terminus in HT1080 cells (Figure 8A and $8 \mathrm{~B}$ ). In addition, overexpressing the C-terminus of the cortactin phosphorylation mimic also inhibited cell migration (Figure $8 \mathrm{~A}$ and $8 \mathrm{~B}$ ). Thus, the C-termini of cortactin and the phosphorylation mimic interfere with the ability of native cortactin to regulate cell migration.

The tyrosine phosphorylation of the cortactin C-terminus was essential for its inhibitory effect on cell migration. Cell migration was not inhibited by the phosphorylation-incompetent cortactin C-terminus (Figure $8 \mathrm{~A}$ and $8 \mathrm{~B}$ ). The presence of the non-phosphorylated cortactin $\mathrm{C}$-terminus did not affect the function of phosphorylated cortactin. In summary, the increased turnover of the cortactin phosphorylation mimic at focal adhesions increased F-actin dynamics and promoted cell migration. The stable association of the phosphorylation-incompetent cortactin at focal adhesions reduced F-actin dynamics and inhibited cell migration. Truncating the $\mathrm{N}$-terminal $\mathrm{F}$-actin binding domains did not affect F-actin dynamics. The stable association of the phosphorylation-incompetent cortactin C-terminus at focal adhesions appears to be independent of F-actin dynamics and then had no effect on cell motility. However, the mechanism by which the C-terminus of the cortactin phosphorylation mimic interferes with cellular phosphorylated cortactin and inhibits cell migration requires further study.

\section{Discussion}

At focal adhesions, Src and FAK form an active kinase complex to phosphorylate associated proteins. The identification of cortactin, a Src kinase substrate and F-actin associated protein [10], as a FAK interactor at focal adhesions suggests that FAK-Src-catalyzed cortactin tyrosine phosphorylation is involved in the regulation of cell motility (Figure 4). Src was the first oncogene to be discovered and is one of the most intensely studied [1-3]. In cancer cells, active Src not only increases cell growth and survival, but also promotes actin cytoskeleton reorganization and decreases cell-cell and cellmatrix adhesions to facilitate motility and invasiveness $[1,3]$. Cortactin is frequently overexpressed in malignant tumors and there is a correlation between cortactin phosphorylation and enhanced cell migration and metastasis $[35,36]$. Cortactin and its tyrosine phosphorylation are involved in adhesion-dependent cell edge protrusion [37]. Cortactin is phosphorylated by Src at the leading edge of lamellipodia, where in association with the Arp $2 / 3$ complex, it initiates the branching of actin filaments to promote the formation of membrane protrusions $[36,38]$. The overexpression of constitutively active Src appears to induce cortactin phosphorylation and membrane protrusions at the edge (Figure 6D and $6 \mathrm{E})$. Cell migration and invasion are essential elements of cancer metastasis. During cancer cell invasion, cortactin is one of the proteins that direct actin bundles to form invadopodia [39]. The involvement of Src-catalyzed cortactin phosphorylation in cell motility control suggests cortactin might be a crucial regulator of cancer metastasis.

For cell migration, the turnover of the cytoskeleton at focal adhesions is more important than stable association. To propel cell movement, the dynamic interplay between the actin cytoskeleton and cell adhesion sites induces membrane protrusions and generates traction force. The external force exerted on the cell and the internal force generated by the F-actin cytoskeleton during cell migration are anchored and sensed at focal adhesions, particularly by the FAK-Src complex $[32,40]$. One method of cell motility control by the FAK-Src complex is the phosphorylation of FAK associated proteins such as paxillin and p130Cas [40]. Mutating the FAK-Src phosphorylation sites in paxillin $\left(\mathrm{Tyr}^{31,118}\right)$ inhibits the turnover of focal adhesions and reduces cell motility [41]. Cortactin is phosphorylated by the FAKSrc complex at C-terminal tyrosine residues $\left(\mathrm{Tyr}^{421}, 466\right.$, 475,482 ; Figure 6) $[8,9]$. The structural configuration of cortactin, which contains $\mathrm{N}$-terminal F-actin binding domains and C-terminal FAK association domains, enables it to mediate the association between the Factin cytoskeleton and focal adhesions (Figure 4) [19]. By regulating the interaction between the cortactin Cterminus and FAK, cortactin tyrosine phosphorylation is able to control the association or dissociation of F-actin at focal adhesions. This hypothesis is supported by the results of the phosphorylation-incompetent cortactin mutant (Y421/466/475/482F) and its N-terminal domain truncated form. Blocking tyrosine phosphorylation by mutating Tyr into Phe (Y421/466/475/482F) stabilizes the interaction of cortactin with FAK, decreases the turnover of F-actin at focal adhesions and inhibits cell migration (Figure 4D and 8). By truncating the N-terminal $\mathrm{F}$-actin binding domains, the remaining cortactin $\mathrm{C}$ terminus can no longer interact with F-actin. Its association or dissociation at focal adhesions has no effect on F-actin dynamics-the inhibitory effect on cell migration by the stably-associated phosphorylation-incompetent cortactin could be reversed by truncating the $\mathrm{N}$-terminal F-actin binding domains (Figure 8B).

The reduced interaction between the cortactin phosphorylation mimic and FAK suggests that cortactin 
dissociates from focal adhesions after being phosphorylated (Figure 4D). Our results and those of others indicate that the cortactin phosphorylation mimic promotes focal adhesion turnover and increases cell migration (Figure 8) [34]. It is very likely that cortactin tyrosine phosphorylation by the FAK-Src complex dissociates cortactin from focal adhesions and promotes F-actin turnover. The inhibition of cell migration by the $\mathrm{N}$ terminal truncated cortactin phosphorylation mimic implies additional functions for tyrosine phosphorylated cortactin (Figure 8). Without the $\mathrm{N}$-terminal F-actin binding domains, the phosphorylation mimic $\mathrm{C}$-terminal can no longer interact with the $\mathrm{F}$-actin cytoskeleton. This suggests that the C-terminus of the cortactin phosphorylation mimic interferes with the ability of cortactin to regulate motility. Importantly, the C-terminus of the phosphorylation-incompetent cortactin mutant does not have a similar inhibitory effect on cell migration (Figure 8). Thus, the effect of the cortactin phosphorylation mimic C-terminus on cell migration is phosphorylation specific. The wild-type cortactin $\mathrm{C}$-terminus can also inhibit cell migration because it can be phosphorylated within the cell (Figure 6B and 8). It is not clear what functions are perturbed by the cortactin phosphorylation mimic C-terminus. FAK autophosphorylation and centrosome orientation, which are important for cell motility control, are not affected by the cortactin C-terminal mutants (Figure $8 \mathrm{C}$ and $8 \mathrm{D}$ ). Further study is required to clarify the role of the cortactin phosphorylation mimic C-terminus on cell migration.

\section{Conclusions}

In summary, we demonstrate that cortactin is recruited by FAK into focal adhesions, where it is phosphorylated by the FAK-Src complex. The interaction between FAK and cortactin is mediated by the SH3 domain and the proline-rich region and is regulated by FAK-Src complex-catalyzed cortactin tyrosine phosphorylation. Cortactin at focal adhesions can further recruit cortactin interacting proteins. The structure of cortactin, which contains $\mathrm{N}$-terminal $\mathrm{F}$-actin binding domains and $\mathrm{C}$ terminal FAK association domains, allows it to function as a bridge between the F-actin cytoskeleton and focal adhesions. After the tyrosine phosphorylation of cortactin by the FAK-Src complex, the reduced interaction of cortactin with FAK leads to an increased turnover of the associated F-actin at focal adhesions. These changes in local F-actin dynamics ultimately regulate cell motility.

\section{Methods}

\section{Materials}

Anti-FAK, anti-phosphotyrosine ${ }^{397}$ FAK, anti-Src, antiphosphotyrosine ${ }^{418} \mathrm{Src}$, anti-p130Cas and anti-phosphotyrosine ${ }^{410}$ p130Cas antibodies were purchased from Cell
Signaling (Danvers, MA, USA). Anti-phosphotyrosine ${ }^{421}$ cortactin, anti-phosphotyrosine ${ }^{466}$ cortactin, anti- $\alpha$ tubulin and anti-myc tag primary antibodies were from Sigma (St. Louis, MO, USA). DAPI, phalloidin, and horseradish peroxidase-conjugated secondary antibodies were also from Sigma. Anti-phosphotyrosine ${ }^{482}$ cortactin antibody was from Chemicon. Anti-cortactin, anti-phosphotyrosine and anti-EGFP antibodies were from Santa Cruz Biotechnology (Santa Cruz, CA, USA). Anti-paxillin antibody was from Transduction Laboratories (San Jose, CA, USA). The fluorescence secondary antibodies (Alexa Fluor 488/546/647 conjugates) for immunofluorescence were from Invitrogen (Carlsbad, CA, USA). PP2 was from Calbiochem (San Diego, CA, USA). The Leica laser scanning confocal microsystem, including the Leica TCS SP2 confocal microscope, the Leica confocal scanner and the Leica confocal acquisition software, was used with the HCX PL APO 1bd. BL 63.0X/1.4 oil objective at 1.4 numerical aperture at a working temperature of $22^{\circ} \mathrm{C}$. The fluorescence medium was Sigma's DABCO.

\section{Cell culture, immunofluorescence staining, immunoprecipitation and western blotting}

COS7 cells, HEK293 cells, HT1080 cells and NIH3T3 cells were cultured in Dulbecco's modified Eagle's medium (DMEM) supplemented with 10\% calf serum. For immunofluorescence staining, cells cultured on glass coverslips were fixed in $3.7 \%$ formaldehyde and $0.18 \%$ Triton X-100 in phosphate-buffered saline for $10 \mathrm{~min}$. The fixed cells were stained with primary and secondary antibodies [42]. The detailed characterization on the specificity of the phospho-cortactin antibodies (anti-phosphotyrosine ${ }^{421}$ cortactin antibody, anti-phosphotyrosine ${ }^{466}$ cortactin antibody and anti-phosphotyrosine ${ }^{482}$ cortactin antibody) is provided in the supplementary data of our previous publication [23]. For immunoprecipitation, cells were lysed in $1 \%$ Triton X100 buffer containing $50 \mathrm{mM}$ HEPES $\mathrm{pH} 7.4,2.5 \mathrm{mM}$ EDTA, $150 \mathrm{mM} \mathrm{NaCl}, 30 \mathrm{mM} \beta$-glycerophosphate, $1 \mathrm{mM}$ sodium orthovanadate, $1 \mathrm{mM}$ PMSF and $2 \mu \mathrm{l} / \mathrm{ml}$ protease inhibitor cocktail. After centrifugation at $12000 \mathrm{~g}$ for 15 min at $4^{\circ} \mathrm{C}$ to remove cell debris, the supernatant (500$1000 \mu \mathrm{g}$ protein) was mixed with $1.5 \mu \mathrm{g}$ primary antibody for immunoprecipitation [43]. For western blotting, the sample in $1 \times$ SDS sample buffer with $20 \mathrm{mM}$ dithiothreitol was heated at $100^{\circ} \mathrm{C}$ for $5 \mathrm{~min}$, subjected to SDS-PAGE and then transferred to an Immobilon-P membrane (Millipore, Billerica, MA). Western blotting was conducted as previously described [43]. The target proteins were detected using enhanced chemiluminescence.

\section{Construction and expression of cortactin, FAK and Src mutants and the analysis of their interactions}

Murine cortactin cDNA, N-terminus (from aa 1 to 329), C-terminus (from aa 330 to 546), phosphorylation- 
incompetent mutant (Y421/466/475/482F), phosphorylation mimicking mutant (Y421/466/475/482E) and SH3domain deletion mutant (from aa 1 to 500) were constructed into GFP-tagged, myc-tagged or GST-tagged expression vectors. Murine FAK cDNA, FERM (from aa 1 to 400), $\triangle$ FERM (from aa 401 to 1052), $\triangle$ FRNK (from aa 1 to 692), kinase domain (From aa 401 to 692), FRNK (from aa 693 to 1052), FAT (from aa 919 to 1052), FRNK m1 [FRNK mutant 1 (P712/715A)], FRNK m2 [FRNK mutant 2 (P876/879A)], FRNK m1/2 [FRNK mutant (P712/715/876/879A)] and the autophosphorylation-incompetent mutant (Y397F) were constructed into GFP-tagged expression vectors. The constitutively active Src (Y527F) and the inactive Src (K295M) were constructed from chicken Src. These tagged fusion proteins were expressed in cells by transient transfection following the protocol for Invitrogen's Lipofectamine 2000. The experiments were carried out 48 hours after transfection.

For co-immunoprecipitation, GFP-tagged fusion proteins were expressed in COS7 cells and the cell lysates were immunoprecipitated with anti-FAK antibody. For GST pull-down assays, GST-tagged cortactin was expressed in E. coli and isolated using glutathione-agarose beads. The lysates of HEK293 cells expressing GFPtagged FAK mutants were incubated with GST-tagged cortactin bound to glutathione-agarose beads. The proteins were dissolved with $1 \times$ SDS sample buffer and detected by western blotting.

\section{Cortactin tyrosine phosphorylation}

HEK293 or HT1080 cells were resuspended in DMEM with $0.5 \%$ bovine serum albumin and plated onto culture dishes pretreated with $20 \mu \mathrm{g} / \mathrm{ml}$ fibronectin overnight and $1 \%$ Bovine serum albumin for 1 hour (Millipore-protocol). The cells were harvested at 10, 30 and $120 \mathrm{~min}$ for immunoprecipitation, immunofluorescence staining and western blotting. Suspended cells were considered $0 \mathrm{~min}$, and normal cultured cells were adherent.

For RNA interference, COS7 cells were transfected with FAK stealth siRNA (5'-GGUUCAAGCUGGAUUAUUUTT-3'), cortactin stealth siRNA (5'-AUCUCUCUGUGACUCGUGCUUCUCCTT-3') or Luciferase control siRNA (5'-CGUACGCGGAAUACUUCGATT$\left.3^{\prime}\right)$ at a final concentration of $80 \mathrm{nM}$ following the protocol provided by Invitrogen. For expression of fusion proteins, COS7 and HEK293 cells were transfected with vector expressing GFP-tagged or myc-tagged fusion proteins. Forty-eight hours after transfection, cortactin tyrosine phosphorylation was analyzed.

\section{Cell migration and statistical analysis}

In HT1080 cells, RNA interference was used to knock down cortactin or FAK. GFP-tagged proteins were expressed by transient transfection. Forty-eight hours after transfection, the cells were transferred onto plates with a glass bottom for live-cell microscopic imaging and cultured overnight. Cells were then transferred to Leibovitz's L15 medium with 10\% FBS and mounted on a Leica MDW live-cell imaging station with a $37^{\circ} \mathrm{C}$ heated platform and a $20 \times$ lens, and photographed every $3 \mathrm{~min}$. The images were processed with Image J software on NIH Java and cells were tracked with Manual Tracking in Image J software. The position of the nuclear center for each cell was tracked, recorded and calculated for average migration speed in a 6 -hour period. Eight viewfields were analyzed, and the cell numbers are indicated in the figures. For cortactin and FAK RNAi experiments, cells were randomly selected for analysis. For cells expressing GFP-tagged fusion proteins, only GFP positive cells were selected for analysis. Data are presented as mean \pm SD. Differences were analyzed using Student's ttest. $P<0.05$ was considered statistically significant.

The inhibition of cell migration by the Src family kinase inhibitor, PP2 [33], was assessed with the woundhealing assay. An HT1080 cell monolayer was scratched with a rubber policeman, washed with phosphate-buffer saline twice and fed with Leibovitz's L15 medium with $10 \%$ FBS in the presence or absence of $10 \mu \mathrm{M}$ PP2. The cells were then mounted on the live-cell imaging station on a $37^{\circ} \mathrm{C}$ heated platform and $10 \times$ lens and photographed every $4 \mathrm{~min}$.

\section{Acknowledgements}

This work was supported by grants 2010 CB912102 and 2006CB910703 from the Ministry of Science and Technology of China, 30821065 and 30870559 from the China National Nature Sciences Foundation, and 07DZ05907 from Shanghai Municipal Committee of Science and Technology.

\section{Authors' contributions}

WW performed plasmid construction, localization immunofluorescence, cell migration assays, immunoprecipitations and GST pull-downs. YL performed plasmid construction, localization immunofluorescence, cell transfections, protein phosphorylation analysis, immunoprecipitations and GST pull-downs. $\mathrm{KL}$ conceived of the study, participated in its design and coordination and drafted the manuscript. All authors read and approved the final manuscript.

Received: 21 June 2011 Accepted: 13 November 2011

Published: 13 November 2011

\section{References}

1. Guarino M: Src signaling in cancer invasion. J Cell Physiol 2010, 223:14-26.

2. Thomas SM, Brugge JS: Cellular functions regulated by Src family kinases. Annu Rev Cell Dev Biol 1997, 13:513-609.

3. Yeatman TJ: A renaissance for Src. Nat Rev Cancer 2004, 4:407-480.

4. Summy JM, Gallick GE: Src family kinases in tumor progression and metastasis. Cancer Metastasis Rev 2003, 22:337-358.

5. Shor AC, Keschman EA, Lee FY, Muro-Cacho C, Letson GD, Trent JC, Pledger WJ, Jove R: Dasatinib inhibits migration and invasion in diverse human sarcoma cell lines and induces apoptosis in bone sarcoma cells dependent on Src kinase for survival. Cancer Res 2007, 67:2800-2808.

6. Kanner SB, Reynolds AB, Vines RR, Parsons JT: Monoclonal antibodies to individual tyrosine-phosphorylated protein substrates of oncogeneencoded tyrosine kinases. Proc Natl Acad Sci USA 1990, 87:3328-3332. 
7. Wu H, Reynolds AB, Kanner SB, Vines RR, Parsons JT: Identification and characterization of a novel cytoskeleton-associated pp60src substrate. Mol Cell Biol 1991, 11:5113-5124.

8. Huang C, Liu J, Haudenschild CC, Zhan X: The role of tyorsine phosphorylation of cortactin in the locomotion of endothelial cells. J Biol Chem 1998, 273:25770-25776

9. Martin KH, Jeffery ED, Grigera PR, Shabanowitz J, Hunt DF, Parsons JT: Cortactin phosphorylation sites mapped by mass spectrometry. J Cell Sci 2006, 119:2851-2853.

10. Weed SA, Parsons JT: Cortactin: coupling membrane dynamics to cortical actin assembly. Oncogene 2001, 20:6418-6434

11. Bryce NS, Clark ES, Leysath JL, Currie JD, Webb DJ, Weaver AM: Cortactin promotes cell motility by enhancing lamellipodial persistence. Curr Biol 2005, 15:1276-1285.

12. Illes A, Enyedi B, Tamas P, Bogel G, Melinda, Lukacs, Buday L: Cortactin is required for integrin-mediated cell spreading. Immun Lett 2006, 104:124-130.

13. van Rossum AG, Moolenaar WH, Schuuring E: Cortactin affects cell migration by regulating intercellular adhesion and cell spreading. Exp Cell Res 2006, 312:1658-1670.

14. Vuori K, Ruoslahti E: Tyrosine phosphorylation of p130Cas and cortactin accompanies integrin-mediated cell adhesion to extracellular matrix. $J$ Biol Chem 1995, 270:22259-22262

15. Lai FP, Szczodrak M, Oelkers JM, Ladwein M, Acconcia F, Benesch S, Auinger S, Faix J, Small JV, Polo S, Stradal TE, Rottner K: Cortactin promotes migration and platelet-derived growth factor-induced actin reorganization by signaling to Rho-GTPases. Mol Biol Cell 2009, 20:3209-3223.

16. Jia L, Uekita T, Sakai R: Hyperphosphorylated cortactin in cancer cells plays an inhibitory role in cell motility. Mol Cancer Res 2008, 6:654-662.

17. Wu H, Parsons JT: Cortactin, an $80 / 85$-kilodalton pp60Src substrate, is a filamentous actin-binding protein enriched in the cell cortex. J Cell Biol 1993, 120:1417-1426

18. Weaver AM, Karginov AV, Kinley AW, Weed SA, Li Y, Parsons JT, Cooper JA: Cortactin promotes and stabilizes Arp2/3-induced actin filament network formation. Curr Biol 2001, 11:370-374.

19. Daly RJ: Cortactin signaling and dynamic actin networks. Biochem J 2004, 382:13-25.

20. DeMali KA, Wennerberg K, Burridge $K$ : Integrin signaling to the actin cytoskeleton. Curr Opin Cell Biol 2003, 15:572-582.

21. Welch MD, Mullins RD: Cellular control of actin nucleation. Annu Rev Cell Dev Biol 2002, 18:247-288.

22. Brakebusch C, Fassler $\mathrm{R}$ : The integrin-actin connection, an enternal love affair. EMBO J 2003, 22:2324-2333.

23. Wang $W$, Chen L, Ding $Y$, Jin J, Liao K: Centrosome separation driven by actin-microfilaments during mitosis is mediated by centrosomeassociated tyrosine-phosphorylated cortactin. J Cell Sci 2008, 121:1334-1343.

24. Shi Q, Boettiger D: A novel mode for integrin-mediated signaling: tethering is required for phosphorylation of FAKY397. Mol Biol Cell 2003, 14:4306-4315

25. Toutant M, Costa A Studler JM, Kadare G, Carnaud M, Girault JA: Alternative splicing controls the mechanisms of FAK autophosphorylation. Mol Cell Boil 2002, 22:7731-7743.

26. Mitra SK, Hanson DA, Schlaepfer DD: Focal adhesion kinase: in command and control of cell motility. Nat Rev Mol Cell Biol 2005, 6:56-68

27. Parsons JT: Focal adhesion kinase: the first ten years. J Cell Sci 2003, 15:1409-1416

28. Schaller MD, Hildebrand JD, Shannon JD, Fox JW, Vines RR, Parsons JT: Autophosphorylation of the focal adhesion kinase, pp125FAK, directs SH2-dependent binding of pp60src. Mol Cell Biol 1994, 14:1680-1688.

29. Calalb MB, Polte TR, Hanks SK: Tyrosine phosphorylation of focal adhesion kinase at sites in the catalytic domain regulates kinase activity: a role for Src family kinases. Mol Cell Biol 1995, 15:954-963.

30. Sieg DJ, Hauck CR, Ilic D, Klingbeil CK, Schaefer E, Damsky CH, Schlaepfer DD: FAK integrates growth-factor and integrin signals to promote cell migration. Nat Cell Biol 2000, 2:249-256.

31. Giannone G, Dubin-Thaler BJ, Rossier O, Cai Y, Chaga O, Jiang G, Beaver W, Dobereiner $H$, Freund Y, Borisy G, Sheetz MP: Lamellipodial actin mechanically links myosin activity with adhesion-site formation. Cell 2007, 128:561-575
32. Ilic D, Furuta Y, Kanazawa S, Takeda N, Sobue K, Nakatsuji N, Nomura S, Fujimoto J, Okada M, Yamamoto T, Aizawa S: Reduced cell motility and enhanced focal adhesion contact formation in cells from FAK-deficient mice. Nature 1995, 377:539-544

33. Hanks J, Gardner JP, Dow RL, Changelian PS, Brissette WH, Weringer EJ, Pollok BA, Connelly PA: Discovery of a novel, potent, and Src familyselective tyrosine kinase inhibitor. Study of Lck-and FynT-dependent T cell activation. J Biol Chem 1996, 271:695-701.

34. Kruchten AD, Krueger EW, Wang Y, McNiven MA: Distinct phospho-forms of cortactin differentially regulate actin polymerization and focal adhesions. Am J Physiol Cell Physiol 2008, 295:1113-1122.

35. Boyer B, Bourgeois $Y$, Poupon MF: Src kinase contributes to the metastasis spread of carcinoma cells. Oncogene 2002, 21:2347-2356.

36. Rothschild BL, Shim AH, Ammer AG, Kelley LC, Irby KB, Head JA, Chen L, Varella-Garcia M, Sacks PG, Frederick B, Raben D, Weed SA: Cortactin overexpression regulates actin-related protein $2 / 3$ complex activity, motility and invasion in carcinomas with chromosome 11q13 amplification. Cancer Res 2006, 66:8017-8025.

37. Lapetina S, Mader CC, Machida K, Mayer BJ, Koleske AJ: Arg interacts with cortactin to promote adhesion-dependent cell edge protrusion. J Cell Biol 2009, 185:503-519.

38. Ammer AG, Weed SA: Cortactin Branches Out: Roles in Regulating Protrusive Actin Dynamics. Cell Motil Cytoskeleton 2008, 65:687-707.

39. Artym W, Zhang Y, Seillier-Moiseiwitsch F, Yamada KM, Mueller SC: Dynamic interactions of cortactin and membrane type 1 matrix metalloproteinase at invadopodia: defining the stage of invadopodia formation and function. Cancer Res 2006, 66:3034-3043.

40. Webb DJ, Donais K, Whitmore LA, Thomas SM, Turner CE, Parsons JT, Horwitz AF: FAK-Src signalling through paxillin, ERK and MLCK regulates adhesion disassembly. Nat Cell Biol 2004, 6:154-161.

41. Deakin NO, Turner CE: Paxillin comes of age. J Cell Sci 2008, 121:2435-2444

42. Huo H, Guo X, Hong S, Jiang M, Liu X, Liao K: Lipid rafts/caveolae are essential for insulin-like growth factor-1 receptor signaling during 3T3L1 preadipocyte differentiation induction. J Biol Chem 2003, 278:11561-11569.

43. Jin S, Zhai B, Qiu Z, Wu J, Lane MD, Liao K: c-Crk, a substrate of the insulin-like growth factor-1 receptor tyrosine kinase, functions as an early signal mediator in the adipocyte differentiation process. $J$ Biol Chem 2000, 275:34344-34352

doi:10.1186/1471-2121-12-49

Cite this article as: Wang et al:: Tyrosine phosphorylation of cortactin by the FAK-Src complex at focal adhesions regulates cell motility. BMC Cell Biology 2011 12:49.

\section{Submit your next manuscript to BioMed Central and take full advantage of:}

- Convenient online submission

- Thorough peer review

- No space constraints or color figure charges

- Immediate publication on acceptance

- Inclusion in PubMed, CAS, Scopus and Google Scholar

- Research which is freely available for redistribution

Submit your manuscript at www.biomedcentral.com/submit
C Biomed Central 